\title{
Factors associated with the need for a complete denture in one arch or both arches among the elderly population
}

\section{Valmir Vanderlei GOMES FILHO(a) Rafael da Silveira MOREIRA(b) Manoelito Ferreira SILVA JUNIOR(c) Brunna Verna Castro GONDINHO(d) Denise de Fátima Barros \\ CAVALCANTE(a) \\ Jaqueline Vilela BULGARELI(e) Luciane Miranda GUERRA(a) (D) \\ Antonio Carlos FRIAS(f) (D) \\ Marcelo de Castro MENEGHIM(a) \\ Antonio Carlos PEREIRA ${ }^{(a)}$}

(a) Universidade de Campinas - Unicamp, Piracicaba School of Dentistry, Department of Community Dentistry, Piracicaba, SP, Brazil.

(b)Fundação Oswaldo Cruz, Aggeu Magalhães Research Center, Recife, PE, Brazil.

(c) Universidade Estadual de Ponta Grossa - UEPG, Department of Dentistry, Ponta Grossa, PR, Brazil.

(d) Universidade Estadual do Piauí - UESPI, Faculty of Dentistry and Nursing, Department of Dentistry, Parnaíba, PI, Brazil.

(e) Universidade Federal de Uberlândia - UFU, Department of Dentistry, Uberlândia, MG, Brazil.

(f) Univeridade de São Paulo - USP, School of Dentistry, Department of Community Dentistry, São Paulo, SP, Brazil.

Declaration of Interests: The authors certify that they have no commercial or associative interest that represents a conflict of interest in connection with the manuscript.

Corresponding Author:

Antônio Carlos Pereira

E-mail: apereira111@gmail.com

https://doi.org/10.1590/1807-3107bor-2020.vol34.0040

Submitted: November 6, 2019

Accepted for publication: March 3, 2020

Last revision: April 4, 2020
Abstract: This study aimed to identify factors associated with the need for complete dentures in one dental arch or both, among the elderly population. The cross-sectional household study was conducted with a representative sample of elderly people (65 years or older) in the state of São Paulo, Brazil, in 2015. The dependent variable was the need for complete dentures (in one arch or both), and independent variables were socioeconomic and demographic conditions, social capital, self-perception of oral health and access to dental services. Simple and multinomial logistic regression models tested effect measures ( $p<0.05)$. A total of 5,948 elderly people participated. Results indicated that those with greater chances of needing a complete denture in one arch were male ( $\mathrm{OR}=1.54$; C195\%:1.04-2.29), with fewer household goods (OR = 2.25; C195\%:1.50-3.38), lower monthly household income: $\mathrm{R} \$ 501-1500$ (OR $=3.44$; C195\%:1.27-9.35), $\mathrm{R} \$ 1501-$ 2500 (OR = 4.11; CI95\%:1.50-11.27), R \$2501-4500 (OR = 2.76; C195\%:1.106.95), self-reported need for a complete denture (OR $=4.75$; CI95\%:3.08$7.35)$, $\geq 3$ years since last dental appointment ( $\mathrm{OR}=1.80$; C195\%:1.06-3.05), and dissatisfaction with last dental appointment (OR $=1.80$; CI95\%:1.063.05). There were more chances of the need for complete dentures in both arches among older elders (OR $=1.44$; C195\%:1.06-1.88), with lower monthly household income: $\mathrm{R} \$<501$ (OR = 4.45; C195\%:1.71-11.60), $\mathrm{R} \$ 501-1500 \quad(\mathrm{OR}=4.01 ; \mathrm{Cl} 95 \%: 2.14-7.51), \mathrm{R} \$ 1501-2500 \quad(\mathrm{OR}=2.95$; C195\%:1.64-5.32), < 3 years of education (OR = 1.45; C195\%:1.13-1.85), feeling unhappy $(\mathrm{OR}=2.74$; C195\%:1.35-5.57), self-reported need for a complete denture (OR = 8.48; C195\%:5.75-12.50), dissatisfaction with their mouth $(\mathrm{OR}=2.38$; C195\%:1.64-3.46), $\geq 3$ years since last dental appointment $(\mathrm{OR}=$ 4.28; C195\%:2.85-6.43), and dissatisfaction with last dental appointment (OR $=4.28$; CI95\%:2.85-6.43). The several dimensions of the determinants of the need for a complete denture reflect the influence of both demographic and socioeconomic aspects, social capital, self-perception of oral health and access to dental services.

Keywords: Oral Health; Tooth Loss; Denture, Complete.

\section{Introduction}

Among the several health areas in Brazil, oral health has not been a priority of health actions and services historically, despite the high prevalence of caries and periodontal disease, the main consequences 
of edentulism. ${ }^{1}$ Complete tooth loss constitutes a serious public health problem and is responsible for deleterious physical and emotional consequences. ${ }^{2,3}$

According to the National Oral Health Survey (SB Brazil) 2003 and 2010, edentulism is declining in Brazil among adolescents and middle-aged adults, but the situation remains precarious for the older adult and elderly population. ${ }^{4}$ Although the need for prosthetic rehabilitation has seen a substantial decrease for young adults, it will continue to increase for the elderly in the next decades. ${ }^{4,5}$

Edentulism affects elderly people more, ${ }^{5}$ and is undeniable in Brazil's aging population ${ }^{6}$, bearing in mind that the elderly population is expected to increase from $12.6 \%$ to $25.1 \%$ from 2013 to 2025.7 Therefore, it is critical to understand the process of population aging, and the impacts that it has on life and health conditions. In this respect, oral health actions should be viewed more in line with reality.

Most studies in the literature have analyzed the use of dental prostheses jointly with its need, or have not distinguished among the types of prostheses analyzed. ${ }^{8,9}$ In view of the foregoing, the present study has an original scope, since it sought to analyze the factors associated with the need for a prosthesis, considering a complete denture in one dental arch or both. Therefore, the objective this study was to identify the factors associated with this need for a complete denture in one dental arch or both among the elderly population.

\section{Methodology}

\section{Study design and ethical aspects}

The cross-sectional study was conducted in the state of São Paulo in 2015 (SB São Paulo) and had the approval of the Research Ethics Committee of FOPUNICAMP, protocol 094/2015.

\section{Sample}

The SBSão Paulo study is population-based survey, and was conducted in the state of São Paulo, Brazil, in 2015, for the purpose studying the oral health conditions of the over 65-year elderly population. ${ }^{10}$

The sample was designed as a conglomerate in two stages, with probability proportional to population size (PPP), considering the sample weight and effect of designs in the respective stages of the design. In the first step, the state of São Paulo was stratified into six regions, which we called "domains." A total of 33 cities were drawn for each domain, which we called Primary Sampling Units (PSUs), except for region 1 (Metropolitan Area of the São Paulo State Capital), for which 12 cities were drawn, plus the capital. In the second stage, two census sectors (Census Sampling Units - CSUs) were drawn for each city drawn, also respecting the PPP in the sectors. ${ }^{10}$ Hence, the absolute frequency has not be shown, because it does not represent the true value, only the relative frequency.

Sample size was defined based on frequency estimation, variability to be investigated, and acceptable margin of error. The results of the SB Brazil 2010 survey ${ }^{11}$ provided the estimates for the city of São Paulo (Region 1 - Capital and Metropolitan Area of São Paulo) and for southeastern São Paulo (Regions 2 to 6$)^{10}$

In 2015, the state of São Paulo had 41 million inhabitants distributed throughout 645 municipalities, in that the capital concentrated 10 million inhabitants. Accordingly, there were different municipalities with different demographic densities and different human development indexes. The stratification strategy was adopted to improve the precision of the data obtained, by allowing more precise estimates to be provided for each stratum of the population within each domain, which had a defined geopolitical distribution. Thus, independent draws of the domains and weights were performed, and were later included in the data analysis for correction of results. The sampling system scheme is shown in Figure 1.

The sample size was estimated for elders 65 years or older, and the study adopted a design effect (deff) of 2.0 , error margin of $8.0 \%$, confidence interval of $95.0 \%$, and a non-response rate of $30.0 \%$. The sample size for the 65 or older age group was $5,948 .^{10}$

\section{Data collection}

The epidemiological examinations and interviews were conducted at the volunteers' home by previously trained and calibrated dentists, using the consensus 


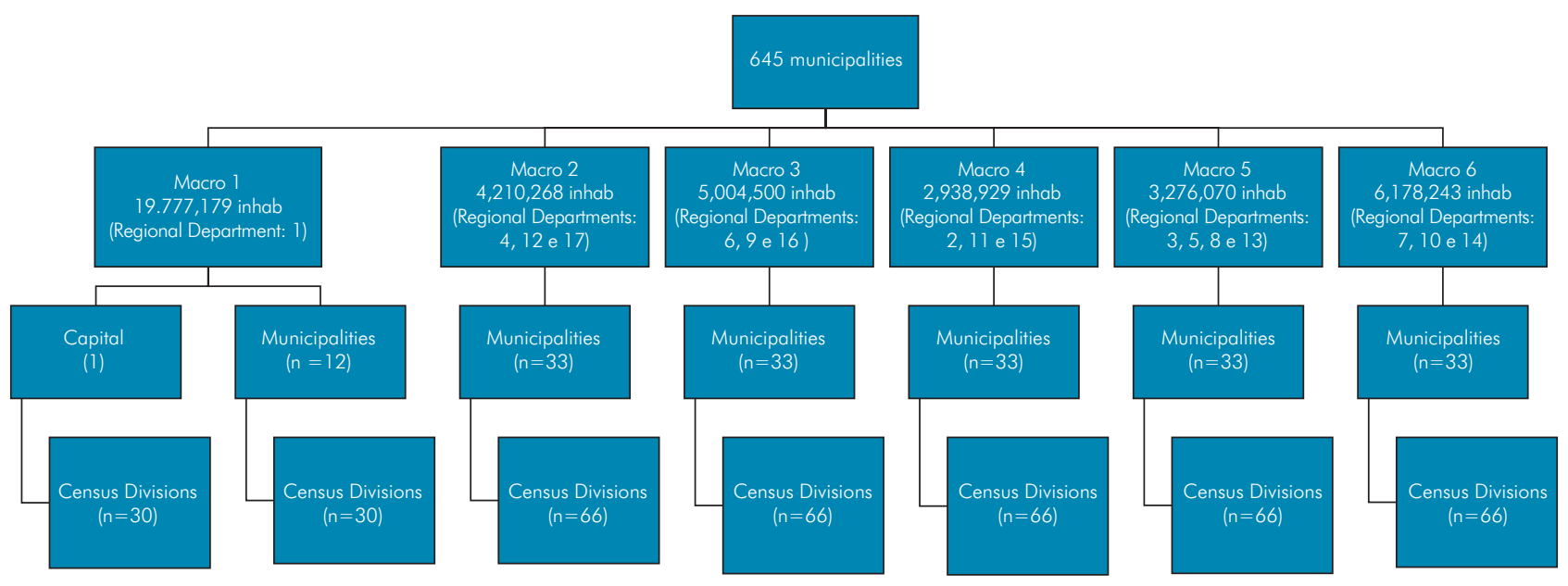

Figure 1. Sample design flowchart.

technique. The minimum accepted kappa value for each examiner and disease studied was $0.652 .{ }^{10}$

The team's calibration process lasted a minimum of 24 working hours, and contemplated the theoretical and practical aspects of the indexes used. The percentage of intra- and interexaminer agreement was measured to establish the reproducibility of the study. ${ }^{10}$

In the SB São Paulo 2015 survey, ${ }^{10}$ the oral exams were performed to evaluate the need for dental prosthesis based on the World Health Organization recommendations stated in the $4^{\text {th }}$ edition of its Instruction Manual of Basic Epidemiological Surveys in Oral Health, with the adjustments expressed in the SB Brazil 2010 Project. ${ }^{11}$ In addition to this, a questionnaire was applied to the individuals examined at their home, which contained questions related to demographic and socioeconomic characterization, self-perception of oral health, social capital and access to dental services.

\section{Study variables}

The dependent variable was the need for complete denture stratified into one arch or both arches, analyzed for Code 4, which is the need for a dental prosthesis, based on the WHO criteria. The independent variables were divided into four blocks, according to the theoretical model adopted ${ }^{12}$ (Figure 2):

a. Block 1 (demographic and socioeconomic factors): age (< 71 years or $\geq 71$ years); sex (female or male); ethnicity/color (white or not white); number of persons/rooms $(<1$ person or $\geq 1$ person); number of household goods ( $<7$ household goods or $\geq 7$ household goods); monthly household income in reals $(\mathrm{R} \$)(\leq 501$, 501 to 1500,1501 to 2500,2501 to $4500, \geq 4501$ ) and education ( $<3$ or $\geq 3$ years);

b. Block 2 (social capital): cooperation in problem-solving (likely, indifferent or unlikely cooperation); feeling of security (secure, regular or insecure); feeling of happiness (happy, indifferent or unhappy);

c. Block 3 (self-perception of oral health): Need for a complete denture (need or no need); oral impacts on daily performance $(\mathrm{OIDP}=0$ or OIDP $\geq 1)$; satisfaction with their mouth (satisfied, regular or dissatisfied);

d. Block 4 (access to dental services): last dental appointment ( $<1$ year, 1 to 2 years or $\geq 3$ years); type of service of last dental appointment (private health, healthcare insurance or public health service); reason for last dental appointment (routine, pain, extraction or others); satisfaction with last dental appointment (satisfied, regular or dissatisfied).

\section{Data analysis}

The outcome (need or no need for a complete denture in at least one dental arch or in both) was associated with the explanatory variables separated 


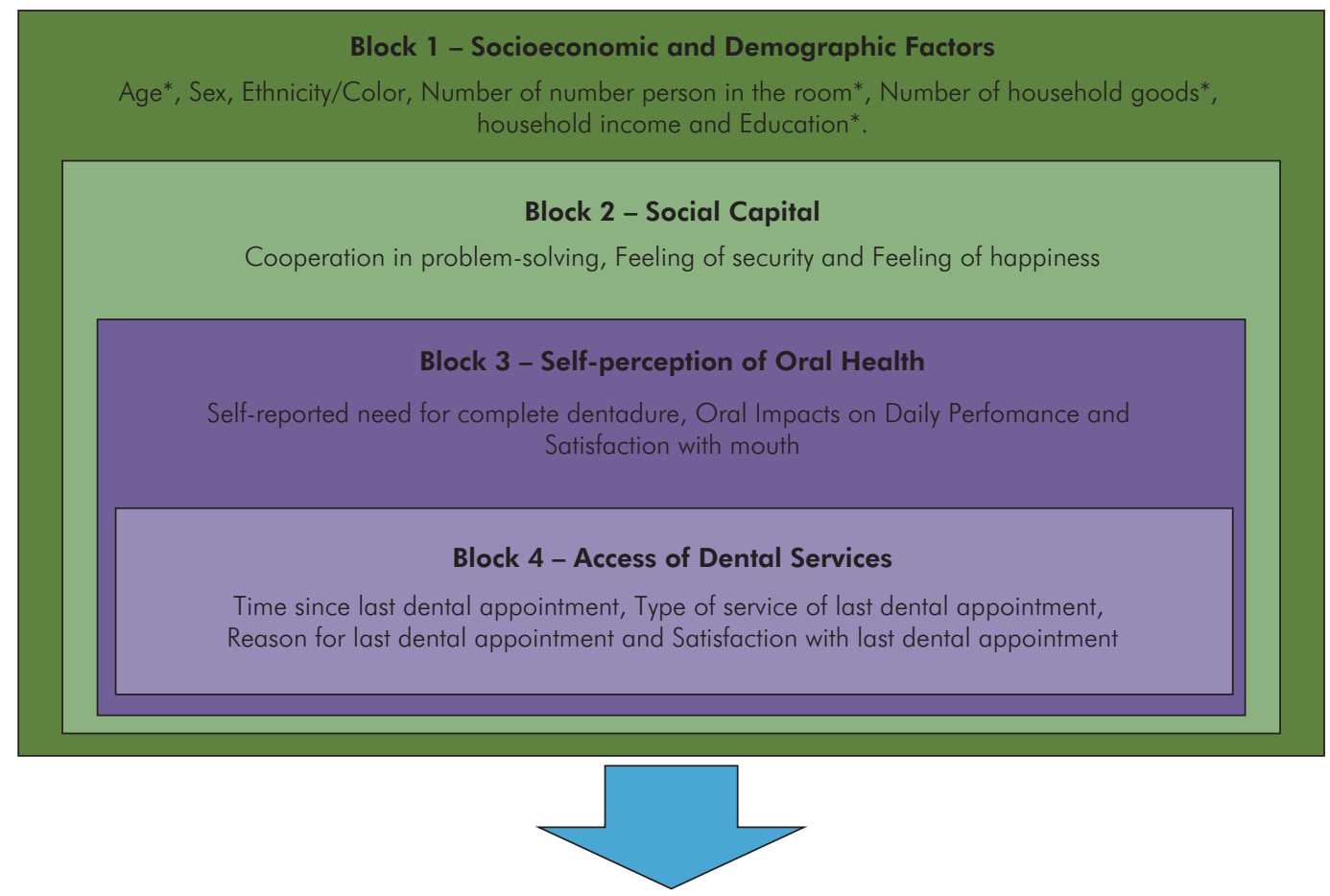

\section{Need for Complete Denture}

*Variable dichotomized by median

Figure 2. Theoretical model adapted for the study.

into 4 blocks, according to the theoretical model adopted. ${ }^{12}$ The blocks represented socioeconomic and demographic factors, social capital, self-perception of oral health and access to dental services, respectively (Figure 2). Of these categories, the "no need" condition was used as a reference for the analyses developed. The simple and multinomial logistic regression models were calculated, and the association strength was expressed by the odds ratio (OR) with a confidence interval (CI) of $90.0 \%$.

The data analysis was initially described according to Pearson's chi-square test adjusted using the RaoScott correction, considering the complex sample design, with respective weights and sampling strata. After performing the simple analysis, independent variables with $p$-value $<0.25$ were eligible for multilevel analysis, as supported by the literature. ${ }^{11}$ The forward method was applied to perform the multilevel model method $(\mathrm{p}<0.05){ }^{13}$
Several multilevel analyses were performed to determine the multilevel model in each block, starting with the variables belonging to the most distal block, in which they were introduced into the model one by one (forward method), until only the variables statistically associated with the outcome remained $(p<0.05)$. The same step was repeated for the subsequent level (intermediate and proximal) to analyze the variables of subsequent levels, whereas the variables of the previous level were retained, even though the statistical significance changed.

\section{Results}

Data was analyzed on 5,948 individuals aged 65 years or older, representative of the state of São Paulo. Most of the elderly participants were older white women (> 71 years old), with a monthly household income between R \$501-1500, and < 3 years of education (Table 1). 
Table 1. Description of independent variables according to dependent variable $(n=5,948)$.

\begin{tabular}{|c|c|c|c|c|c|}
\hline \multirow{3}{*}{ Variables } & \multicolumn{5}{|c|}{ Need for complete denture } \\
\hline & Total & No need & In one arch & In both arches & \multirow{2}{*}{ p-value } \\
\hline & $(\%)$ & $(\%)$ & $(\%)$ & (\%) & \\
\hline \multicolumn{6}{|c|}{ Block 1 - Demographic and socioeconomic factors } \\
\hline \multicolumn{6}{|l|}{ Age* } \\
\hline$<71$ years & 47.0 & 49.2 & 9.1 & 41.7 & 0.164 \\
\hline$\geq 71$ years & 53.0 & 44.5 & 9.2 & 46.3 & \\
\hline \multicolumn{6}{|l|}{ Sex } \\
\hline Female & 64.7 & 48.7 & 8.7 & 42.6 & 0.119 \\
\hline Male & 35.3 & 43.0 & 10.0 & 47.0 & \\
\hline \multicolumn{6}{|l|}{ Ethnicity/Color } \\
\hline White & 67.1 & 47.1 & 9.4 & 43.5 & 0.701 \\
\hline Not white & 32.9 & 45.8 & 8.7 & 45.5 & \\
\hline \multicolumn{6}{|l|}{ Persons/room* } \\
\hline$<1$ person & 54.6 & 49.3 & 8.8 & 41.9 & 0.269 \\
\hline$\geq 1$ person & 45.4 & 44.7 & 8.7 & 46.5 & \\
\hline \multicolumn{6}{|c|}{ Number of household goods* } \\
\hline$<7$ goods & 39.8 & 54.6 & 6.8 & 38.6 & $0.001^{* *}$ \\
\hline$\geq 7$ goods & 60.2 & 42.2 & 10.0 & 47.8 & \\
\hline \multicolumn{6}{|c|}{ Household income ( $\mathrm{R} \$$ month) } \\
\hline$<501$ & 4.2 & 37.1 & 5.8 & 57.1 & $<0.001^{* *}$ \\
\hline $501-1500$ & 49.6 & 41.6 & 8.2 & 50.2 & \\
\hline $1501-2500$ & 31.8 & 48.3 & 11.7 & 40.0 & \\
\hline 2501 to 4500 & 10.8 & 62.8 & 7.8 & 29.4 & \\
\hline$\geq 4501$ & 3.6 & 77.9 & 2.8 & 19.3 & \\
\hline \multicolumn{6}{|l|}{ Education* } \\
\hline$<3$ years & 50.6 & 53.0 & 9.0 & 38.0 & $<0.001^{* *}$ \\
\hline$\geq 3$ years & 49.4 & 40.8 & 7.8 & 51.4 & \\
\hline \multicolumn{6}{|l|}{ Block 2 - Social capital } \\
\hline \multicolumn{6}{|c|}{ Cooperation in problem-solving } \\
\hline Likely cooperation & 74.9 & 47.5 & 8.3 & 44.2 & 0.203 \\
\hline Indifferent & 11.7 & 53.1 & 8.6 & 38.3 & \\
\hline Unlikely cooperation & 13.4 & 39.5 & 11.6 & 48.9 & \\
\hline \multicolumn{6}{|l|}{ Feeling of security } \\
\hline Secure & 58.9 & 46.6 & 9.1 & 44.3 & 0.734 \\
\hline Regular & 11.2 & 46.7 & 6.2 & 47.1 & \\
\hline Insecure & 29.9 & 48.1 & 9.2 & 42.7 & \\
\hline \multicolumn{6}{|l|}{ Feeling of happiness } \\
\hline Happy & 83.9 & 49.3 & 8.9 & 41.9 & $0.002^{* *}$ \\
\hline Indifferent & 9.2 & 40.8 & 6.0 & 53.2 & \\
\hline Unhappy & 6.9 & 28.5 & 11.4 & 60.1 & \\
\hline
\end{tabular}

Continue 
- Factors associated with the need for a complete denture in one arch or both arches among the elderly population

\begin{tabular}{|c|c|c|c|c|c|}
\hline \multicolumn{6}{|l|}{ Continuation } \\
\hline \multicolumn{6}{|c|}{ Need for complete denture } \\
\hline No need & 48.6 & 72.8 & 7.1 & 20.1 & $<0.001^{* *}$ \\
\hline Need & 51.4 & 23.6 & 10.6 & 65.8 & \\
\hline \multicolumn{6}{|c|}{ Oral Impacts on Daily Performance } \\
\hline $\mathrm{OIDP}=0$ & 73.0 & 52.2 & 8.9 & 38.9 & $<0.001^{* *}$ \\
\hline OIDP $\geq 1$ & 27.0 & 37.8 & 8.5 & 53.7 & \\
\hline \multicolumn{6}{|l|}{ Satisfaction with mouth } \\
\hline Satisfied & 60.2 & 59.7 & 8.7 & 31.7 & $<0.001^{* *}$ \\
\hline Regular & 15.2 & 41.5 & 9.1 & 49.4 & \\
\hline Dissatisfied & 24.6 & 22.4 & 9.5 & 68.1 & \\
\hline \multicolumn{6}{|c|}{ Block 4 - Access to dental services } \\
\hline \multicolumn{6}{|c|}{ Time since last dental appointment } \\
\hline$<1$ year & 27.1 & 69.5 & 7.7 & 22.9 & $<0.001^{* *}$ \\
\hline $1-2$ years & 19.6 & 60.5 & 9.3 & 30.2 & \\
\hline$\geq 3$ years & 53.3 & 33.5 & 9.1 & 57.5 & \\
\hline \multicolumn{6}{|c|}{ Type of service of last dental appointment } \\
\hline Private health service & 59.9 & 50.1 & 9.5 & 40.4 & $0.013^{* *}$ \\
\hline Health insurance & 5.1 & 51.5 & 5.5 & 43.0 & \\
\hline Public health service & 35.0 & 42.5 & 8.6 & 48.9 & \\
\hline \multicolumn{6}{|c|}{ Reason for last dental appointment } \\
\hline Routine & 16.2 & 61.7 & 11.2 & 27.1 & $<0.001^{* *}$ \\
\hline Pain & 5.6 & 40.8 & 3.5 & 55.7 & \\
\hline Extraction & 18.8 & 30.6 & 7.4 & 62.0 & \\
\hline Other & 59.4 & 50.0 & 9.4 & 40.6 & \\
\hline \multicolumn{6}{|c|}{ Satisfaction with last dental appointment } \\
\hline Satisfied & 87.6 & 50.5 & 8.6 & 40.9 & $0.002^{* *}$ \\
\hline Regular & 8.0 & 38.0 & 8.1 & 53.9 & \\
\hline Dissatisfied & 4.4 & 22.9 & 10.1 & 67.0 & \\
\hline
\end{tabular}

*Dichotomized by the median. **With statistically significant difference after adjusting the data $(\mathrm{p}<0.05)$.

In Table 2, following application of the adjusted analysis, there was a greater chance of the need for a complete denture in one arch among males $(\mathrm{OR}=1.54$; CI95\%: 1.04-2.29), with fewer household goods (OR $=2.25$; CI95\%: 1.50-3.38), low income: $\mathrm{R} \$ 501-1500$ (OR = 3.44; CI95\%: 1.27-9.35), $\mathrm{R} \$ 1501-2500(\mathrm{OR}=4.11 ; \mathrm{CI95 \%}: 1.50-11.27)$, $\mathrm{R} \$ 2501-4500$ (OR = 2.76; CI95\%: 1.10-6.95), self-reported need for a complete denture $(\mathrm{OR}=4.75$; $\mathrm{C} 195 \%$ : $3.08-7.35), \geq 3$ years since last dental appointment $(\mathrm{OR}=1.80 ; \mathrm{CI} 95 \%$ : 1.06--3.05), and dissatisfaction with the last dental appointment $(\mathrm{OR}=1.80$; CI95\%: 1.06-3.05).

In Table 3, following application of the adjusted analysis, there was a greater chance of the need for a complete denture in both arches among older elders (OR = 1.44; CI95\%: 1.06-1.88), with low household income: $\mathrm{R} \$ 501-1500(\mathrm{OR}=4.01$; CI95\%: 2.14-7.51), R $\$<501$ (OR = 4.45; C195\%: 1.71-11.60), $\mathrm{R} \$ 1501-2500$ (OR = 2.95; CI95\%: 1.64-5.32), < 3 years of education $(\mathrm{OR}=1.45$; CI95\%: 1.13-1.85), selfreported need for a complete denture $(\mathrm{OR}=8.48$; 
Table 2. Crude and adjusted analysis of the model of multinomial logistic regression for need for complete denture in one arch among elderly residents in State of São Paulo, Brazil, 2015 ( $n=5,948)$.

\begin{tabular}{|c|c|c|c|c|c|c|}
\hline \multirow{3}{*}{ Variabl+B2:H6les } & \multicolumn{5}{|c|}{ Need for complete denture in both arches } & \multirow{3}{*}{ p-value } \\
\hline & OR & \multirow{2}{*}{$95 \% \mathrm{Cl}$} & \multirow{2}{*}{ p-value } & OR & \multirow{2}{*}{$95 \% \mathrm{Cl}$} & \\
\hline & Crude & & & Adjusted & & \\
\hline \multicolumn{7}{|c|}{ Block 1 - Demographic and socioeconomic factors } \\
\hline \multicolumn{7}{|l|}{ Age $^{*}$} \\
\hline$<71$ years & 1.00 & - & & 1.00 & - & \\
\hline$\geq 71$ years & 1.23 & $0.96-1.56$ & 0.094 & 1.41 & $1.06-1.88$ & $0.020^{* *}$ \\
\hline \multicolumn{7}{|l|}{ Sex } \\
\hline Female & 1.00 & - & & & & \\
\hline Male & 1.25 & $0.98-1.59$ & 0.070 & & & \\
\hline \multicolumn{7}{|l|}{ Ethnicity/Color } \\
\hline White & 1.00 & - & & & & \\
\hline Not white & 1.08 & $0.87-1.32$ & 0.485 & & & \\
\hline \multicolumn{7}{|l|}{ Persons/room* } \\
\hline$<1$ person & 1.00 & - & & & & \\
\hline$\geq 1$ person & 1.22 & $0.92-1.63$ & 0.170 & & & \\
\hline \multicolumn{7}{|c|}{ Number of household goods* } \\
\hline$<7$ goods & 1.61 & $1.19-2.17$ & 0.002 & 1.17 & $0.83-1.65$ & 0.374 \\
\hline$\geq 7$ goods & 1.00 & - & & 1.00 & - & \\
\hline \multicolumn{7}{|c|}{ Household income ( $R \$ /$ month) } \\
\hline$<501$ & 6.25 & $2.73-14.25$ & $<0.001$ & 4.45 & $1.71-11.60$ & $0.002^{* *}$ \\
\hline $501-1500$ & 4.89 & $2.85-8.40$ & $<0.001$ & 4.01 & $2.14-7.51$ & $<0.001^{* *}$ \\
\hline $1501-2500$ & 3.35 & $1.96-5.72$ & $<0.001$ & 2.95 & $1.64-5.32$ & $<0.001^{* *}$ \\
\hline $2501-4500$ & 1.90 & $1.13-3.21$ & 0.016 & 1.66 & $0.98-2.83$ & 0.060 \\
\hline$\geq 4501$ & 1.00 & - & & 1.00 & - & \\
\hline \multicolumn{7}{|l|}{ Education* } \\
\hline$<3$ years & 1.75 & $1.39-2.21$ & $<0.001$ & 1.45 & $1.13-1.85$ & $0.003^{* *}$ \\
\hline$\geq 3$ years & 1.00 & - & & 1.00 & - & \\
\hline \multicolumn{7}{|l|}{ Block 2 - Social capital } \\
\hline \multicolumn{7}{|c|}{ Cooperation in problem-solving } \\
\hline Likely cooperation & 1.00 & - & & & & \\
\hline Indifferent & 0.78 & $0.56-1.07$ & 0.126 & & & \\
\hline Unlikely cooperation & 1.33 & $0.88-2.01$ & 0.176 & & & \\
\hline \multicolumn{7}{|l|}{ Feeling of security } \\
\hline Secure & 1.00 & - & & & & \\
\hline Regular & 1.06 & $0.66-1.69$ & 0.806 & & & \\
\hline Insecure & 0.93 & $0.72-1.21$ & 0.590 & & & \\
\hline \multicolumn{7}{|l|}{ Feeling of happiness } \\
\hline Happy & 1.00 & - & & 1.00 & - & \\
\hline Indifferent & 1.54 & $1.04-2.26$ & 0.030 & 1.43 & $0.98-2.10$ & 0.066 \\
\hline Unhappy & 2.48 & $1.41-4.36$ & 0.002 & 2.74 & $1.35-5.57$ & $0.005^{* *}$ \\
\hline
\end{tabular}

Continue 


\begin{tabular}{|c|c|c|c|c|c|c|}
\hline \multicolumn{7}{|l|}{ Continuation } \\
\hline Block 3 - Self-perception o & alth & & & & & \\
\hline \multicolumn{7}{|c|}{ Self-reported need for complete denture } \\
\hline No need & 1.00 & - & & 1.00 & - & \\
\hline Need & 10.08 & $7.22-14.07$ & $<0.001$ & & $5.75-12.50$ & $<0.001^{* *}$ \\
\hline \multicolumn{7}{|c|}{ Oral Impacts on Daily Performance } \\
\hline $\mathrm{OIDP}=0$ & 1.00 & - & & & & \\
\hline OIDP $\geq 1$ & 1.91 & $1.53-2.38$ & $<0.001$ & & & \\
\hline \multicolumn{7}{|l|}{ Satisfaction with mouth } \\
\hline Satisfied & 1.00 & - & & 1.00 & - & \\
\hline Regular & 2.24 & $1.51-3.34$ & $<0.001$ & 1.14 & $0.65-2.01$ & 0.640 \\
\hline Dissatisfied & 5.72 & $4.28-7.63$ & $<0.001$ & 2.38 & $1.64-3.46$ & $<0.001^{* *}$ \\
\hline \multicolumn{7}{|c|}{ Block 4 - Access to dental services } \\
\hline \multicolumn{7}{|c|}{ Time since last dental appointment } \\
\hline$<1$ year & 1.00 & - & & 1.00 & - & \\
\hline $1-2$ years & 1.52 & $1.09-2.11$ & 0.013 & 1.27 & $0.78-2.11$ & 0.349 \\
\hline$\geq 3$ years & 5.22 & $3.76-7.24$ & $<0.001$ & 4.28 & $2.85-6.43$ & $<0.001^{* *}$ \\
\hline \multicolumn{7}{|c|}{ Type of service of last dental appointment } \\
\hline Private health service & 1.00 & - & & & & \\
\hline Healthcare insurance & 1.03 & $0.71-1.50$ & 0.859 & & & \\
\hline Public health service & 1.42 & $1.08-1.88$ & 0.012 & & & \\
\hline \multicolumn{7}{|c|}{ Reason for last dental appointment } \\
\hline Routine & 1.00 & - & & & & \\
\hline Pain & 3.11 & $1.56-6.18$ & 0.001 & & & \\
\hline Extraction & 4.61 & $3.04-7.00$ & $<0.001$ & & & \\
\hline Other & 1.85 & $1.32-2.59$ & $<0.001$ & & & \\
\hline \multicolumn{7}{|c|}{ Satisfaction with last dental appointment } \\
\hline Satisfied & 1.00 & - & & 1.00 & - & \\
\hline Regular & 1.75 & $0.94-3.24$ & 0.075 & 1.27 & $0.78-2.11$ & 0.349 \\
\hline Dissatisfied & 3.62 & $1.95-6.72$ & $<0.001$ & 4.28 & $2.85-6.43$ & $<0.001^{* *}$ \\
\hline
\end{tabular}

${ }^{*}$ Dichotomized by the median. ${ }^{* *}$ With statistically significant difference after adjusting the data $(p<0.05)$.

C195\%: 5.75-12.50), feeling unhappy (OR = 2.74; CI95\%: 1.35-5.57), dissatisfied with their mouth $(\mathrm{OR}=2.38$; $\mathrm{C} 195 \%$ : 1.64-3.46), and dissatisfied with the last dental appointment ( $\mathrm{OR}=4.28 ; \mathrm{CI} 95 \%$ : 2.85-6.43).

\section{Discussion}

The results of the present study pointed out the determinants of the need for a complete denture in multiple dimensions; however, analysis of one arch or both arches separately indicated that some factors were different. The analysis performed confirmed that the criterion should be considered to address this historical problem of lack of dental care in the elderly Brazilian population. The evidence of population aging and the change in the oral epidemiological pattern in Brazil points to the urgent need to prioritize the inclusion of elderly dental needs in the nation's oral health policies, such as oral rehabilitation.

According to data from the SB Brazil 2010 survey, $76.5 \%$ of the Brazilian elderly population used a prosthesis, and $63.1 \%$ used complete dentures, found to be the most widely used type. ${ }^{11}$ Likewise, although the state of São Paulo is the most highly developed state in 
Table 3. Crude and adjusted analysis of the model of multinomial logistic regression for need for complete denture in both arches among elderly residents in State of São Paulo, Brazil, 2015 ( $n=5,948)$.

\begin{tabular}{|c|c|c|c|c|c|c|}
\hline \multirow{3}{*}{ Variables } & \multicolumn{5}{|c|}{ Need for complete denture in both arches } & \multirow{3}{*}{$\mathrm{p}$-value } \\
\hline & OR & \multirow{2}{*}{$95 \% \mathrm{Cl}$} & \multirow{2}{*}{$p$-value } & OR & \multirow{2}{*}{$95 \% \mathrm{Cl}$} & \\
\hline & Crude & & & Adjusted & & \\
\hline \multicolumn{7}{|c|}{ Block 1 - Demographic and Socioeconomic factors } \\
\hline \multicolumn{7}{|c|}{$\mathrm{Age}^{*}$} \\
\hline$<71$ years & 1.00 & --- & & 1.00 & --- & \\
\hline$\geq 71$ years & 1.23 & $0.96-1.56$ & 0.094 & 1.41 & $1.06-1.88$ & $0.020^{* *}$ \\
\hline \multicolumn{7}{|l|}{ Sex } \\
\hline Female & 1.00 & --- & & & & \\
\hline Male & 1.25 & $0.98-1.59$ & 0.070 & & & \\
\hline \multicolumn{7}{|l|}{ Ethnicity/Color } \\
\hline White & 1.00 & --- & & & & \\
\hline Not white & 1.08 & $0.87-1.32$ & 0.485 & & & \\
\hline \multicolumn{7}{|l|}{ Persons/room } \\
\hline$<1$ person & 1.00 & --- & & & & \\
\hline$\geq 1$ person & 1.22 & $0.92-1.63$ & 0.170 & & & \\
\hline \multicolumn{7}{|l|}{ Number of goods* } \\
\hline$<7$ goods & 1.61 & $1.19-2.17$ & 0.002 & 1.17 & $0.83-1.65$ & 0.374 \\
\hline$\geq 7$ goods & 1.00 & --- & & 1.00 & --- & \\
\hline \multicolumn{7}{|l|}{ Household income $(R \$)$} \\
\hline$<501$ & 6.25 & $2.73-14.25$ & $<0.001$ & 4.45 & $1.71-11.60$ & $0.002^{* *}$ \\
\hline $501-1500$ & 4.89 & $2.85-8.40$ & $<0.001$ & 4.01 & $2.14-7.51$ & $<0.001^{* *}$ \\
\hline $1501-2500$ & 3.35 & $1.96-5.72$ & $<0.001$ & 2.95 & $1.64-5.32$ & $<0.001^{* *}$ \\
\hline $250-4500$ & 1.90 & $1.13-3.21$ & 0.016 & 1.66 & $0.98-2.83$ & 0.060 \\
\hline$\geq 4501$ & 1.00 & --- & & 1.00 & --- & \\
\hline \multicolumn{7}{|l|}{ Education* } \\
\hline$<3$ years & 1.75 & $1.39-2.21$ & $<0.001$ & 1.45 & $1.13-1.85$ & $0.003^{* *}$ \\
\hline$\geq 3$ years & 1.00 & --- & & 1.00 & --- & \\
\hline \multicolumn{7}{|l|}{ Block 2 - Social Capital } \\
\hline \multicolumn{7}{|c|}{ Cooperation in problem-solving } \\
\hline Likely cooperation & 1.00 & --- & & & & \\
\hline Indifferent & 0.78 & $0.56-1.07$ & 0.126 & & & \\
\hline Likely cooperation & 1.33 & $0.88-2.01$ & 0.176 & & & \\
\hline \multicolumn{7}{|l|}{ Feeling of security } \\
\hline Secure & 1.00 & --- & & & & \\
\hline Regular & 1.06 & $0.66-1.69$ & 0.806 & & & \\
\hline Insecure & 0.93 & $0.72-1.21$ & 0.590 & & & \\
\hline \multicolumn{7}{|l|}{ Feeling of happiness } \\
\hline Happy & 1.00 & --- & & 1.00 & --- & \\
\hline Indifferent & 1.54 & $1.04-2.26$ & 0.030 & 1.43 & $0.98-2.10$ & 0.066 \\
\hline Unhappy & 2.48 & $1.41-4.36$ & 0.002 & 2.74 & $1.35-5.57$ & $0.005^{* *}$ \\
\hline
\end{tabular}




\begin{tabular}{|c|c|c|c|c|c|c|}
\hline \multicolumn{7}{|l|}{ Continuation } \\
\hline \multicolumn{7}{|c|}{ Block 3 - Self-perception of oral health } \\
\hline \multicolumn{7}{|c|}{ Self-reported need for complete denture } \\
\hline No need & 1.00 & --- & & 1.00 & --- & \\
\hline Need & 10.08 & $7.22-14.07$ & $<0.001$ & 8.48 & $5.75-12.50$ & $<0.001^{* *}$ \\
\hline \multicolumn{7}{|c|}{ Oral Impacts on Daily Performance } \\
\hline $\mathrm{OIDP}=0$ & 1.00 & --- & & & & \\
\hline OIDP $\geq 1$ & 1.91 & $1.53-2.38$ & $<0.001$ & & & \\
\hline \multicolumn{7}{|c|}{ Satisfaction with mouth } \\
\hline Satisfied & 1.00 & --- & & 1.00 & --- & \\
\hline Regular & 2.24 & $1.51-3.34$ & $<0.001$ & 1.14 & $0.65-2.01$ & 0.640 \\
\hline Dissatisfied & 5.72 & $4.28-7.63$ & $<0.001$ & 2.38 & $1.64-3.46$ & $<0.001^{* *}$ \\
\hline \multicolumn{7}{|c|}{ Block 4 - Access of dental services } \\
\hline \multicolumn{7}{|c|}{ Time of the last dental appointment } \\
\hline$<1$ year & 1.00 & --- & & 1.00 & --- & \\
\hline $1-2$ years & 1.52 & $1.09-2.11$ & 0.013 & 1.27 & $0.78-2.11$ & 0.349 \\
\hline$\geq 3$ years & 5.22 & $3.76-7.24$ & $<0.001$ & 4.28 & $2.85-6.43$ & $<0.001^{* *}$ \\
\hline \multicolumn{7}{|c|}{ Location of the last dental appointment } \\
\hline Private & 1.00 & --- & & & & \\
\hline Health insurance & 1.03 & $0.71-1.50$ & 0.859 & & & \\
\hline Public & 1.42 & $1.08-1.88$ & 0.012 & & & \\
\hline \multicolumn{7}{|c|}{ Reason of the last dental appointment } \\
\hline Routine & 1.00 & --- & & & & \\
\hline Pain & 3.11 & $1.56-6.18$ & 0.001 & & & \\
\hline Extraction & 4.61 & $3.04-7.00$ & $<0.001$ & & & \\
\hline Others & 1.85 & $1.32-2.59$ & $<0.001$ & & & \\
\hline \multicolumn{7}{|c|}{ Satisfaction with the last dental appointment } \\
\hline Satisfied & 1.00 & --- & & 1.00 & --- & \\
\hline Regular & 1.75 & $0.94-3.24$ & 0.075 & 1.27 & $0.78-2.11$ & 0.349 \\
\hline Dissatisfied & 3.62 & $1.95-6.72$ & $<0.001$ & 4.28 & $2.85-6.43$ & $<0.001^{* *}$ \\
\hline
\end{tabular}

Dichotomized by the median. ${ }^{* *}$ With statistically significant difference after adjusting the data $(p<0.05)$.

the country, the data from this survey indicated that its elderly population presented a high percentage of extracted teeth and great need for dentures, especially complete ones. ${ }^{10,11}$

Among the demographic factors associated with the survey, men showed a greater need for prosthesis in only one arch. This aspect may be a direct reflection of the lower motivation to seek dental services and access to them, as well as lower adherence to using a prosthesis among men. ${ }^{9}$ In this study, older elderly people had a greater need for a prosthesis in both arches. Although aging has no direct physiological relationship to tooth loss, the cumulative effect of oral diseases over time leads to edentulism. ${ }^{14,15}$ Aging is also associated with lower adherence to use of a prosthesis over time, commonly because of failures in the preparation, adaptation and/or maintenance of the prosthesis. ${ }^{16,17}$

Socioeconomic factors were associated with the need for a complete denture in one arch and/or both, since a population with lower household income, less education, and a below average number of household goods, has a higher chance of the need for upper and lower complete dentures. This finding is corroborated 
by Matsuyama, ${ }_{18}^{18}$ carried out with older people, which demonstrated an association between denture use and economic status, and which leads us to consider that socioeconomic conditions reverberate in the living and health conditions of the population, including oral health. ${ }^{19}$ Thus, the economic conditions of a nation's inhabitants, especially those subject to social and political inequities, can adversely influence the living conditions of dwellers. ${ }^{20}$

The decrease in quality of life and its impacts can be expressed by the decrease in chewing ability and phonation, as well as nutritional, psychological and aesthetic losses, and the reduction in self-esteem and social integration, ${ }^{20}$ as evidenced by the results found in this study. In the social capital block, elders who were less happy presented a greater need for complete dentures in both dental arches.

In addition, the elders who self-perceived the need to use total prosthesis were associated with both analyses (one arch and both arches). This was also demonstrated in another Brazilian study, ${ }^{9}$ in which the dissatisfaction with their mouth presented a greater need for complete dentures in both arches. Thus, patients must be rehabilitated regarding function and aesthetics to achieve success in prosthetic treatment. This success further enables patients to enjoy psychological well-being and better general health, thus counteracting the consequences of edentulism. ${ }^{20,21,22}$ There is no consensus in the literature about the influence of others factors, such as social, economic, demographic and psychosocial determinants, in the self-perception of oral healthrelated quality of life, thus revealing a low perception of oral health in relation to these factors. ${ }^{23}$

Regarding access to dental services, a longer amount of time since the last dental appointment and dissatisfaction with the last dental appointment were associated with the need for a complete denture in one arch or both. This study showed that access to dental services is still a barrier, especially for the elderly, a population historically excluded from public oral health policies in Brazil. The provision of a total prosthesis is currently contemplated in the National Oral Health Policy, and a considerable number of older people currently wear dentures in Brazil. Data in the literature ${ }^{4,24}$ have shown that a large portion of these dentures must be replaced or repaired. This emphasizes the importance of broadening actions directed toward instituting prosthetic rehabilitation in the Brazilian Unified Health System (SUS). Therefore, the present data analysis based on the SB São Paulo 2015 survey highlights that the National Oral Health Policy must be broadened to include more specific policies for the elderly population, and a more resolute system for making prostheses, such as expanding the supply of total prostheses in primary care..$^{25}$ Other actions of intersectional scope must also be integrated and implemented. ${ }^{19}$

Another factor that should be considered as a parameter for the analysis of healthcare service results is patient satisfaction regarding the care received. ${ }^{26}$ This user-established measure is a sensitive indicator of the quality of service provided. It can subsidize the planning of health programs and policies, and promote more adequate use of services, ${ }^{27}$ although surveys report that some other factors may directly or indirectly influence it, such as sociodemographic factors, health-related factors and attitudes, or subjective factors. ${ }^{28}$

In view of the foregoing, the authors feel that it is important to make the population aware of the need for dentures, particularly regarding the factors that can interfere with preparing health policies that would be coherent with the reality of each region. In this sense, the present study was of unquestionable relevance, because it proposed to analyze a situation based on a theoretical model that considered several sets of variables, despite having the limitation of being cross-sectional. In this type of study, it is difficult to establish causal relationships based on a cross section of time, thus limiting one's confidence in establishing the direction of the association. Moreover, the authors feel that closed questionnaires limit or induce responses, and that some questions depend on the participants' memory. On the other hand, this study had notably strong points, including the use of data from a broadly representative survey, which extended the relevance of the data to other Brazilian states, and other regions and countries with similar characteristics. 
- Factors associated with the need for a complete denture in one arch or both arches among the elderly population

\section{Conclusion}

The need for a complete denture was associated with several dimensions. In one arch, it was associated with demographic and socioeconomic aspects, self-perception of oral health and access to dental services, and in both arches, with demographic and socioeconomic aspects, social capital, self-perception of oral health and access to dental services.

\section{References}

1. Silva DD, Rihs LB, Sousa ML. [Factors associated with maintenance of teeth in adults in the State of São Paulo, Brazil]. Cad Saude Publica. 2009 Nov;25(11):2407-18. Portuguese. https://doi.org/10.1590/S0102-311X2009001100011

2. Papadaki E, Anastassiadou V. Elderly complete denture wearers: a social approach to tooth loss. Gerodontology. 2012 Jun;29(2):e721-7. https://doi.org/10.1111/j.1741-2358.2011.00550.x

3. Emami E, de Souza RF, Kabawat M, Feine JS. The impact of edentulism on oral and general health. Int J Dent. 2013;2013:498305. https://doi.org/10.1155/2013/498305

4. Ministério da Saúde (BR). Cadastro e repasse de recursos para os Laboratórios Regionais de Prótese Dentária: Nota técnica. Brasilia, DF: Ministério da Saúde; 2013.

5. Cunha-Cruz J, Hujoel PP, Nadanovsky P. Secular trends in socio-economic disparities in edentulism: USA, 1972-2001. J Dent Res. 2007 Feb;86(2):131-6. https://doi.org/10.1177/154405910708600205

6. Araújo D. [Epidemiological polarization in Brazil]. Epidemiol Serv Saúde. 2012 Out;21(4):533-8. Portuguese. https://doi.org/10.5123/S1679-49742012000400002.

7. Instituto Brasileiro de Geografia e Estatística - IBGE. População. Brasília, DF: Instituto Brasileiro de Geografia e Estatística; 2010 [cited 2017 Sept 12]. Available from: http://www.ibge.gov.br/home/estatistica/populacao/contagem2007/default.shtm

8. Mallmann HF, Toassi CR, Abegg C. [Epidemiological profile of need and use of dental prosthesis by individuals aged 50-74 years, residents in three Health Districts of the Municipality of Porto Alegre, State of Rio Grande do Sul, Brazil, in 2008]. Epidemiol Serv Saude. 2012 Mar;21(1):79-88. Portuguese. https://doi.org/10.5123/S1679-49742012000100008

9. Azevedo JS, Azevedo MS, Oliveira LJ, Correa MB, Demarco FF. [Needs for dental prostheses and their use in elderly Brazilians according to the National Oral Health Survey (SBBrazil 2010): prevalence rates and associated factors]. Cad Saude Publica. 2017 Aug;33(8):e00054016. Portuguese. https://doi.org/10.1590/0102-311×00054016

10. Pereira AC, Frias AC, Vieira V. Pesquisa estadual de saúde bucal: relatório final. Águas de São Pedro: Livronovo, 2016.

11. Ministério da Saúde (BR). Coordenação Nacional de Saúde Bucal. Secretaria de Vigilância em Saúde. SB Brasil 2010: pesquisa nacional de saúde bucal. Brasília, DF: Ministério da Saúde; 2012.

12. Victora CG, Huttly SR, Fuchs SC, Olinto MT. The role of conceptual frameworks in epidemiological analysis: a hierarchical approach. Int J Epidemiol. 1997 Feb;26(1):224-7. https://doi.org/10.1093/ije/26.1.224

13. Hosmer DW, Lemeshow S. Applied logistic regression. 2nd ed. Danvers: John Wiley \& Sons; 2000. https://doi.org/10.1002/0471722146

14. Silva-Junior MF, Batista MJ, Sousa MLR. Risk factors for tooth loss in adults: a population based prospective cohort study. PLoS ONE. 2019 Jul;14(7):e0219240. https://doi.org/10.1371/journal.pone.0219240

15. Marcenes W, Kassebaum NJ, Bernabé E, Flaxman A, Naghavi M, Lopez A, et al. Global burden of oral conditions in 1990-2010: a systematic analysis. J Dent Res. 2013 Jul;92(7):592-7. https://doi.org/10.1177/0022034513490168

16. Raja BK. Prosthetic status and treatment needs among elder's in old age homes of Bengaluru city, India: a cross-sectional survey. Int J App Dental Sci. 2017;3(3):27-30.

17. Yadav N, Yadav R, Pahuja M, Pardhan S, Miglani S, Malik T. An evaluation of prosthetic status and treatment needs among institutionalized elderly individuals of Delhi, India. Indian J Dent Sci. 2017;9(1):22-5. https://doi.org/10.4103/0976-4003.201635

18. Matsuyama Y, Aida J, Takeuchi K, Tsakos G, Watt RG, Kondo K, et al. Inequalities of dental prosthesis use under universal healthcare insurance. Community Dent Oral Epidemiol. 2014 Apr;42(2):122-8. https://doi.org/10.1111/cdoe.12074

19. Moreira RS, Nico LS, Tomita NE. [The relation between space and collective oral health: for a georeferenced epidemiology]. Cien Saude Colet. 2007 Jan-Mar;12(1):275-84. https://doi.org/10.1590/S1413-81232007000100031

20. Moreira RS, Nico LS, Tomita NE. [Spatial risk and factors associated with edentulism among elderly persons in Southeast Brazil]. Cad Saúde Pública. 2011 Out;27(10):2041-54. Portuguese. https://doi.org/10.1590/S0102-311X2011001000017

21. Chen YF, Yang YH, Chen JH, Lee HE, Lin YC, Ebinger J, et al. The impact of complete dentures on the oral health-related quality of life among the elderly. J Dent Sci. 2012 Aug;7(3):289-95. https://doi.org/10.1016/i.jds.2012.06.004 
22. Bajoria AA, Saldanha S, Shenoy VK. Evaluation of satisfaction with masticatory efficiency of new conventional complete dentures in edentulous patients: a survey. Gerodontology. 2012 Sep;29(3):231-8. https://doi.org/10.1111/i.1741-2358.2012.00634.x

23. Gabardo MC, Moysés ST, Moysés SJ. [Self-rating of oral health according to the Oral Health Impact Profile and associated factors: a systematic review]. Rev Panam Salud Publica. 2013 Jun;33(6):439-45. Portuguese.

24. Aguiar VR, Celeste RK. [The need for, and allocation of, regional prosthodontics laboratories in Brazil: an exploratory study]. Cien Saude Colet. 2015 Oct;20(10):3121-8. Portuguese. https://doi.org/10.1590/1413-812320152010.18212014

25. Ministério da Saúde (BR). Secretaria de Atenção à Saúde. Departamento de Atenção Básica. A saúde bucal no Sistema Único de Saúde. Brasília, DF: Ministério da Saúde; 2018.

26. Esperidião MA, Trad LA. [User satisfaction assessment: theoretical and conceptual concerns]. Cad Saude Publica. 2006 Jun;22(6):1267-76. https://doi.org/10.1590/S0102-311X2006000600016

27. Rodrigues CA, Silva PL, Caldeira AP, Pordeus IA, Ferreira RC, Martins AM. [Factors associated with satisfaction with dental services among the elderly]. Rev Saude Publica. 2012 Dec;46(6):1039-50. Portuguese. https://doi.org/10.1590/S0034-89102013005000008

28. Yamamoto T, Kondo K, Aida J, Suzuki K, Misawa J, Nakade M, et al.; JAGES group. Social determinants of denture/bridge use: japan gerontological evaluation study project cross-sectional study in older Japanese. BMC Oral Health. 2014 Jun;14(1):63. https://doi.org/10.1186/1472-6831-14-63 